\title{
a capitania de minas gerais (1674-1835): modelo de interpretação de uma sociedade agrária'
}

\author{
Angelo Alves Carrara \\ Departamento de História \\ Universidade Federal de Ouro Preto (MG)
}

Ao longo do século XVIII, a produção anual de ouro da Capitania de Minas Gerais foi acompanhada pela importação de mercadorias. No entanto, não ocorreu a mesma correspondência com a produção agrícola e pastoril, e mesmo o fluxo mercantil não esteve, pelo menos a partir de 1765, diretamente vinculado à produção aurífera (gráfico 1).

O crescimento demográfico geral da Capitania no mesmo período também oculta particularidades (gráfico 2). Enquanto a população dos distritos mineradores declinou ou estagnou a partir de 1780 (ano para o qual dispomos das primeiras evidências), as freguesias das áreas de fronteira (Piranga e Rio Pomba) tiveram um crescimento acentuado (gráfico 3).

Estes dados são indícios muito consistentes de que o funcionamento da economia de Minas no período considerado não estava tão estreitamente vinculado à atividade mineradora, como a historiografia até bem recentemente no-lo apresentava. Não obstante, que evidências poderiam esclarecer efetivamente esse funcionamento suposto mais complexo da economia dessa região?

Este trabalho tem por objetivo identificar tais evidências, bem como apresentar um modelo capaz de ordená-las e torná-las coerentes entre si. O período escolhido quer-se justificado pelas seguintes razões: 1674 inaugura o processo de ocupação territorial da Capitania, e em 1835

Este trabalho compendia os resultados das pesquisas apresentadas em Contribuição para a História Agrária de Minas Gerais; séculos XVIII e XIX. Mariana: Edufop, 1999e Agricultura e Pecuária na Capitania de Minas Gerais; 1674-1807. Rio de Janeiro:UFRJ, 1997 (tese de doutorado) e foi em parte apresentado no XI Congresso Nacional de História, realizado entre os dias 22 e 25 de agosto de 2000 em Bogotá, Colômbia. 
Gráfico I Rendimento Total da Capitania de Minas Gerais:

quintos (arrobas), dízimos e entradas de mercadorias (réis) - 1700-1820

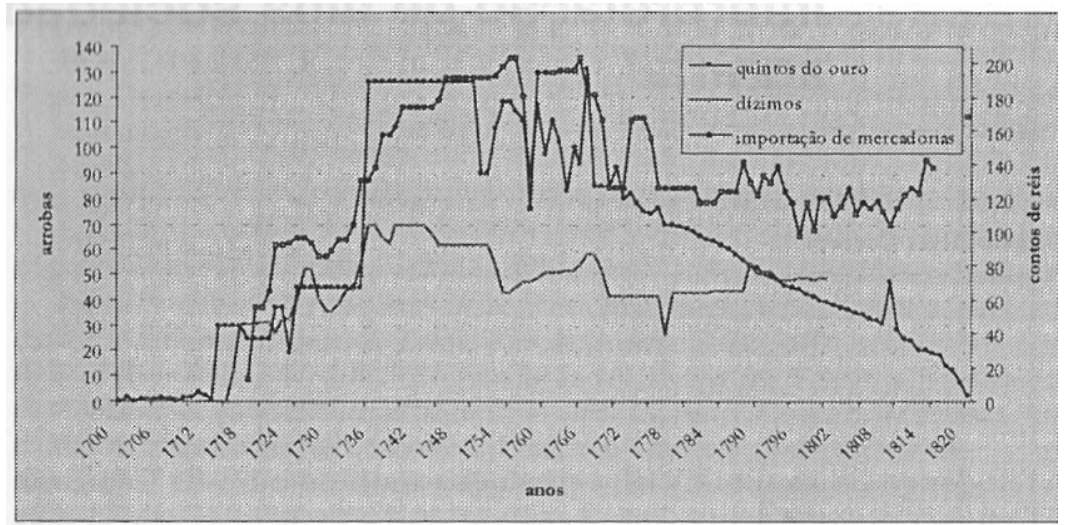

Fontes: Maxwell, Kenneth R. A Devassa da Devassa. Rio de Janeiro: Paz e Terra, 1977; anexo estatístico; Eschwege,Wilhelm L. von. Pluto Brasiliensis. Belo Horizonte: Imprensa Oficial, 1922 [1833]; cap. 4; Matos José Raimundo da Cunha. Corografia Histórica da Província dc Minas Gerais. Belo Horizonte: Arquivo Público Mineiro, 1981 [1837]; parte III, caps. 26/28/29.

Gráfico 2. População total da Capitania de Minas Gerais (1742-1808)

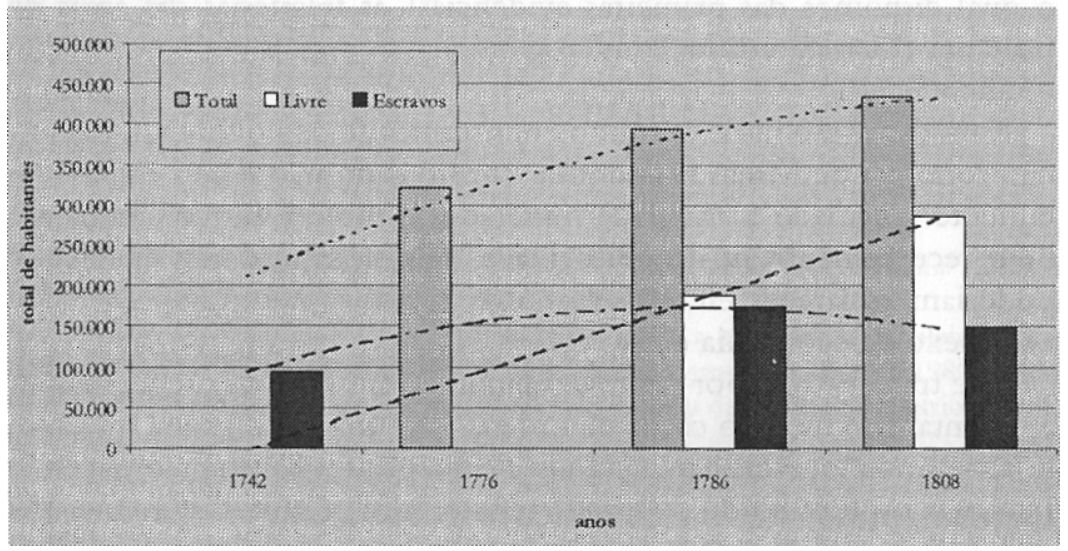

Fontes: Costa, Iraci del Nero da. Populações Mineiras: sobre a estrutura populacional de alguns núcleos mineiros no alvorecer do século XIX. São Paulo, Instituto de Pesquisas Econômicas, 1981. p. 251/287/ 297/309/325/329. Luna, Francisco Vidal \& Costa, Iraci del Nero da. Minas Colonial: economia $e$ sociedade. São Paulo: FIPE/Pioneira, 1982. Fonte: Revista do Arquivo Público Mineiro,Vols.2 (1897),p. 511 e 4 (1899), pp 294-5;. Matos, José Raimundo da Cunha. Corografia Histórica da Província de Minas Gerais.Belo Horizonte:Arquivo Público Mineiro, 1981 [1837],parte III,cap. 1. 


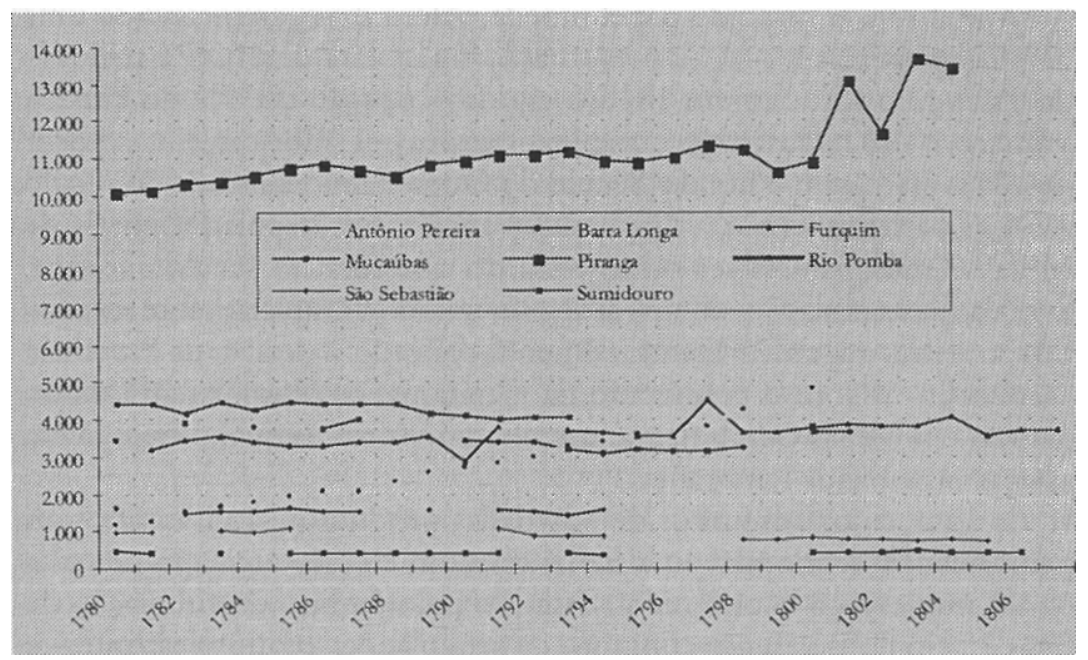

Fonte:Arquivo da Cúria Metropolitana de Mariana. R-12: Registro dos róis dos confessados das freguesias desta Comarca da Cidade (1780-1817).

foi abolida a legislação fiscal do Antigo Regime português, em especial aquela relativa aos dízimos, à entrada de mercadorias e à décima predial. Os dados fiscais contínuos até esse ano amparam, portanto, as afirmações aqui avançadas.Todavia, uma ruptura - superestrutural, sem dúvida, posto que atingia a representação da Capitania - uma ruptura mais profunda deve ser buscada um pouco antes, 1807 foi o último ano em que o ouro em pó - o principal meio de troca e a principal reserva de valor da Capitania, circulou livremente como moeda.

Em 1..$^{\circ}$ de setembro de 1808 foi baixado o alvará proibindo sua circulação, e a 12 de outubro do mesmo ano foi expedido o alvará regulamentando a feitura de bilhetes impressos para o troco do ouro em pó nas casas de permuta. Entre 1808 e 1813, a receita gerada pela produção total de ouro tornou-se equivalente à receita gerada pela produção total da agricultura e da pecuária da Capitania, e não cessou mais de perder importância para esta última. Em 1808, as trinta arrobas do quinto correspondiam a cerca de 746 contos de réis, enquanto que o dízimo total conhecido correspondia a uma cifra próxima de 350 contos. Em 1813, a produção de ouro caíra para pouco mais de 500 contos, valor bem próximo ao da produção agrária. 
Desde então, ocorreram rapidamente outras mudanças, especialmente 0 aumento na emissão do papel moeda. Além disso, anunciava-se uma 'ruptura superestrutural': a perturbação financeira de 1808, a inclusão do Triângulo Mineiro em 1816, a rápida ocupação do Vale do Paraíba mineiro e sua inclusão no complexo agroexportador cafeeiro a partir de 1818, marcaram o fim do 'Século do Ouro' na mentalidade do século XIX. A partir de então, a Capitania, poucos anos depois Província de Minas Gerais, parecia ser outra coisa do que fora no século anterior, livre das determinações da atividade mineradora, completamente submetida aos ritmos agrários. Estruturalmente, contudo, o dealbar da Província confundiu-se com o crepúsculo da Capitania: os últimos registros do dízimo em Minas Gerais flagraram uma província na qual o ourojá era apenas uma pálida lembrança.

As áreas cujos conjuntos de atividades produtivas são identificados pelos termos 'economia' ou 'sistema econômico', são aqui apresentadas como um 'espaço econômico', definido pelo âmbito da circulação de bens e pelo conseqüente conjunto de articulações econômicas intra- e inter-regionais. ${ }^{2}$ Considera-se aqui a economia de Minas Gerais como o conjunto dos modos de produção, escravista e familiar, existentes no seu interior. 'Minas Gerais' apresenta-se como um espaço no qual processos econômicos diversos fundam diversas articulações econômicas regionais. Por conseguinte, suas diferentes 'regiões' são recortadas por padrões diferentes de circulação de bens. A expressão estruturas agrárias corresponde, destarte, nesses modos de produção pré-capitalistas, à quase totalidade das estruturas econômicas de uma dada sociedade, posto que a base econômica de todos eles é a agricultura e/ou a criação de gado. Assim, por estruturas agrárias entende-se aqui o conjunto formado pelas estruturas da produção agrária às quais correspondem as estruturas da circulação dos gêneros produzidos e as estruturas da distribuição da renda gerada por essa circulação.

As categorias "espaço econômico" e "capital mineral circulante" foram tomadas do capítulo "La minería andina colonial", in: Assadourian, Carlos Sempat et alii. Minería y Espacio Económico en los Andes: siglos XVI-XX. Lima, Instituto de Estudios Peruanos, 1980. O emprego desta idéia para interpretar a economia mineradora latino-americana não é nova. Em 1977, o professor Heraclio Bonilla,na apresentação da edição em espanhol do Minas y Mineros en el Peru Colonial; 1776-1826, de John Fisher (Lima: IEP, 1977), já falava de um "espaço peruano".Também o professor Assadourian já havia publicado "La producción de la mercancía dinero en la formación del mercado interno colonial", in Florescano, Enrique (comp.) Ensayos 


\section{O modelo: pressupostos teóricos}

O modelo particular da sociedade agrária vigente em Minas Gerais durante o período colonial aqui considerado assume como pressuposto fundamental o fato de que o ouro extraído e posto em circulação imediatamente (em pó) ou quintado (em barras) no interior da Capitania de Minas funcionou até 1808 como moeda, ou se se preferir, como "capital mineral circulante". ${ }^{3}$ Em decorrência disto, o tempo de duração de todas as empresas mineradoras era determinado pelo rendimento das lavras, ou seja, pela qualidade e pela quantidade dos minerais nas jazidas. Era exatamente isso o que determinava o tamanho da 'fábrica' (particularmente o número dos escravos), e os gastos com ela (alimentação e vestuário dos escravos e manutenção/reposição das ferramentas, por exemplo) - era a produção mineral que sustinha e permitia a reprodução das unidades de produção escravistas. Portanto, a determinação última da atividade mineradora - entendida como a soma combinada dos tempos de duração do conjunto das empresas - era absolutamente interna. Isto quer dizer que o setor minerador não experimentou nenhuma dependência de oscilações de preços ou de demanda externa por seus produtos - ouro e pedras preciosas. A mineração no século XVIII em Minas, por ser, antes de tudo, produção de uma moeda que podia a qualquer momento ser posta em circulação,

sobre el Desarrollo Económico de México y América Latina (1500-1975). México: Fondo de Cultura Económica, 1979. A expressão "espaço econômico" foi posteriormente proposta pelo programa de investigação sobre o ciclo de circulação do capital mineiro e seus efeitos no espaço andino colonial publicado na obra Minería $y$ Espacio Económico en los Andes (siglos XVI-XIX), por Assadourian, Bonilla, Platt e Mitre: sin desconocer la importancia que posee la articulación del espado colonial com la economia europea y el mercado mundial, nuestra principal línea de investigación estará centrada en los procesos y efectos que la producción de metales preciosos ocasiona en el próprio espado andino colonial (p. 23). Cf. também os trabalhos reunidos por Jorge Silva Riquer, Juan Carlos Grosso e Carmen Yuste. Circuitos Mercantiles y Mercados en Latinoamérica; siglos XVIII-XIX. México: Instituto de Investigaciones Dr.José Maria Luis Mora-Instituto de Investigaciones Históricas/UNAM, 1995 (de especial interesse para nosso trabalho são os resultados alcançados por Enrique Tandeter, Vilma Milletich e Roberto Schmit em "Flujos mercantiles en el Potosí colonial tardio").

"...para funcionar como dinheiro, o ouro evidentemente tem de entrar no mercado por algum ponto situado em sua fonte de produção, onde se troca como produto direto do trabalho por outro produto de trabalho do mesmo valor" (Marx, K. O Capital, cap. III, 2). 
fosse em barras ou em pó, independia de financiamentos externos para se implantar.

Por serem incapazes de se auto-abastecerem de gêneros alimentícios, as unidades de produção escravistas do setor minerador (como de sorte a quase totalidade da população vilareja), independentemente de abrigarem ou não em seu interior roças de mantimentos, demandavam das unidades de produção escravistas do setor agrário aqueles produtos que lhes faltavam. Em razão disso, parte do setor escravista agrário consolidou uma produção agrícola e pastoril voltada para o abastecimento dos gêneros demandados pela maioria da população dos núcleos mineradores. Desde a primeira hora em que a arrecadação dos quintos (e, em decorrência, a produção mineral) começou a cair, todas as demais atividades, dependentes da mineração, começaram também a arrefecer, o que era manifesto nas curvas declinantes: a) da importação de mercadorias (representadas pela queda do rendimento dos contratos das entradas); e b) da produção agrícola e pastoril (dadas pela queda do valor dos contratos dos dízimos). Esta proposição, válida para a Capitania de Minas Gerais considerada em seu conjunto, tende todavia a obscurecer as variações regionais.

Evidentemente, as unidades de produção escravistas não abarcavam toda a população da Capitania. Parte significativa da população rural estabeleceu também desde o primeiro momento um padrão de produção rural que se adequa ao conceito de'economia camponesa', conforme o resumo da matéria procedido pelo professor Ciro Flamarion Cardoso. ${ }^{4}$ Desse, modo, a partir da perspectiva do caráter do processo de produção, as unidades produtivas são aqui classificadas segundo a maneira de produzir de cada uma, i. e., segundo um modo de produção escravista (com seus dois setores — minerador e agrário - responsáveis pela maior parte da circulação mercantil da Capitania de Minas Gerais) e um modo de produção camponês, ou familiar,ou parcelar, e que também tinha, na figura do faiscador, o sucedâneo do 'setor minerador'.

Ora, tanto a produção aurífera, quanto a produção agrícola ou pecuária escravistas encontravam-se maximamente concentradas no que respeita à riqueza gerada, e que se destinava em sua maior parte à sustentação e à reprodução do próprio setor, isto é, às compras de escravos, fazenda seca, ferragem, gêneros alimentícios, serviço de oficiais mecânicos e jornais de escravos. Isto significa que os movimentos de importação de

\footnotetext{
${ }^{4}$ Cardoso, Ciro F. S. Agricultura e Capitalismo. Petrópolis: Vozes, 1979. p. 51.
} 
mercadorias e de comercialização da produção agrária referem-se, portanto, na sua ampla maioria, à parcela da sociedade mineira participante do modo de produção escravista. A demanda inicial, inerente e imprenscindível ao modo de produção escravista colonial em Minas Gerais compreende-se assim em ambos os setores minerador e agrário: monopólio de terras e das águas. Desta forma, o limite dos setores desse modo de produção em Minas é o limite dado pelo rendimento das lavras.

O esgotamento das lavras significou também o esgotamento do escravismo naquelas áreas correspondentes. O volume de ouro produzido pelas áreas mineradoras era o limite estrutural da sustentação e da possibilidade de reprodução do escravismo em Minas Gerais. Já no sul da Minas, em Minas Novas e, mais tarde, na zona cafeeira, por exemplo, o limite era dado pela produção agrícola e pecuária sujeita às demandas dos mercados consumidores. Nas regiões onde foi possível a implantação de uma produção econômica voltada para o abastecimento de núcleos fora da Capitania, como o sul de Minas, o escravismo novamente a acompanha.

Dentro dessa perspectiva, a constituição de uma agricultura no sul de Minas independeu completamente da exaustão dos veios. Surgiu da possibilidade de abastecer um mercado cada vez mais emergente: o Rio de Janeiro, que se beneficiara ao longo do século XVIII de sua condição de porto mais importante para a região mineradora.

Não se pode retirar do modo de produção camponês a capacidade de adquirir escravos, o que correspondia a uma anterior capacidade de participar em graus variáveis dos mercados e de alguma atividade agrária mercantil. A própria estrutura da posse de escravos em Minas expressa igualmente os limites desse modo de produção. Não é o campesinato que se responsabilizava pelo maior volume desse abastecimento, apesar de dele ocasionalmente ou mesmo de forma continuada poder participar. Afinal de contas, todo lavrador ou roceiro precisava dispor de alguma produção comercializável, porquanto era no mercado que ia buscar as mercadorias que não produzia e das quais necessitava para a manutenção da sua própria produção (ferramentas e roupas, especialmente). É nesse sentido que produz algum excedente.

Mas, não cabe no caráter da produção escravista destinada ao abastecimento o termo excedente; a razão de ser da sua produção era o mercado. Além disso, havia os inúmeros mundinhos dos mercados a retalho e das trocas miúdas locais - nos sertões mineiros, seus vestígios contemporâneos são os muitos lugares somente denominados "comercinhos" - tão importantes para a constelação de roceiros e pequenos 
lavradores, e que são também a carne e o sangue de seu modo de produção. Mas, a sua própria limitação não encontra muitas fontes nas quais se deixem revelar. É como se a natureza de seu processo de produção se refletisse na exigüidade das fontes que lhes possam iluminar a História.

Deve-se também notar que ambos os modos de produção participam do mesmo nível técnico. Independentemente da natureza do processo produtivo, toda propriedade rural tinha o mesmo nível técnico, a mesma qualidade dos instrumentos de trabalho. Os inventários da maior propriedade rural de Minas — o Vínculo do Jaguara - ou dos mais humildes lavradores não traziam diferenças qualitativas, mas simplesmente quantitativas: era o tamanho da "fábrica" que as distinguia quanto às forças produtivas (mais escravos, mais enxadas e foices, mais terras). Quanto a este último fator, ele eqüivalia na unidade escravista a mais terra para um mesmo proprietário, e numa unidade de tipo camponês, terra nova para domicílios novos, porque não havia serventia para terras em demasia sem fábrica corresponde, nem mecanismos que lhes garantissem a posse. Obviamente, o caráter mercantil da produção escravista lhe permitia incorporar eventuais melhoramentos tecnológicos, muito visíveis nos seus "moinhos moentes e correntes" ou nos seus engenhos de cana.

Porém, se a agricultura e a pecuária de tipo escravista voltadas para o abastecimento interno colonial foram poderosas e eficientes enquanto durou seu tempo, foram as pequenas lavouras de mantimentos e as pequenas criações de gado que garantiam, com uma base técnica restrita, níveis de rendimento agrícola e pastoril tais, que permitiram não só o crescimento ininterrupto da população, como o avanço conseqüente da fronteira agrícola. Se for possível uma imagem, o movimento agrário característico de Minas colonial é o da ampliação constante dessa fronteira por ondas crescentes de pequenos lavradores em todas as direções disponíveis.

\section{Heterogeneidade regional: as muitas Minas}

Retomemos alguns pontos. A Capitania de Minas era um conjunto de regiões economicamente heterogêneas, e, portanto, com ritmos particulares. Isto é firmemente demonstrável pelas diferenças dos dízimos - isto é, dos níveis de produção agrícola - de cada freguesia, das entradas e das exportações de mercadorias. Desde o princípio da ocupação territorial, essas regiões foram fixando determinados padrões de agricultura e pecuária, e uma estrutura de propriedade rústica segundo 
os movimentos regionais da produtividade das lavras ou das demandas dos mercados de fora da Capitania (reses, porcos e fumo do Sul de Minas e algodão de Minas Novas, por exemplo - gráficos 4 e 5). Com base nessa proposição, a 'decadência' deve ser lida como uma queda do nível do comércio interno da Capitania decorrente da menor disponibilidade de moeda, isto é, de ouro em pó.

Gráfico 4. Importação de mercadorias na Comarca de Rio das Mortes - 1765-1818

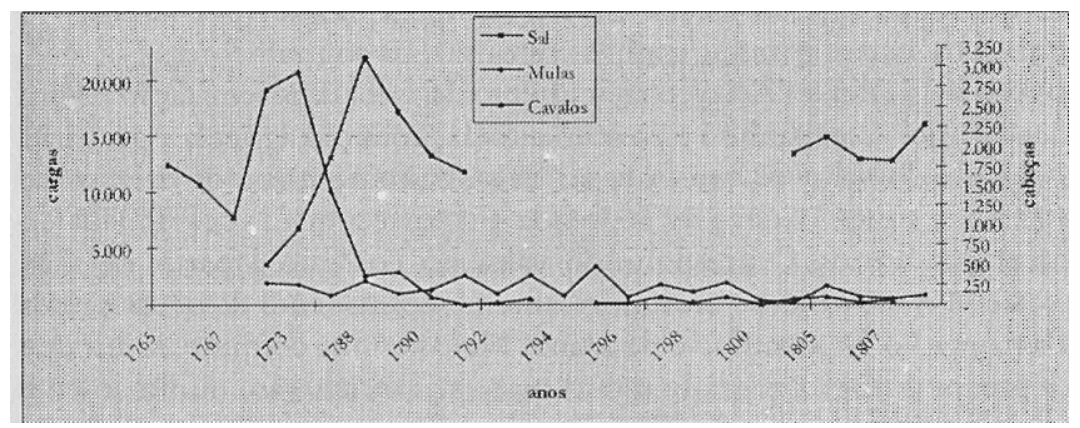

Fonte:Arquivo Nacional, Coleção Casa dos Contos de Ouro Preto, vols., 16,20,728,14,504,1533,15, 23; Arquivo Público Mineiro, Coleção Casa dos Contos CC 455.

Gráfico 5. Exportação de mercadorias pela Comarca de Rio das Mortes - 1802-1811

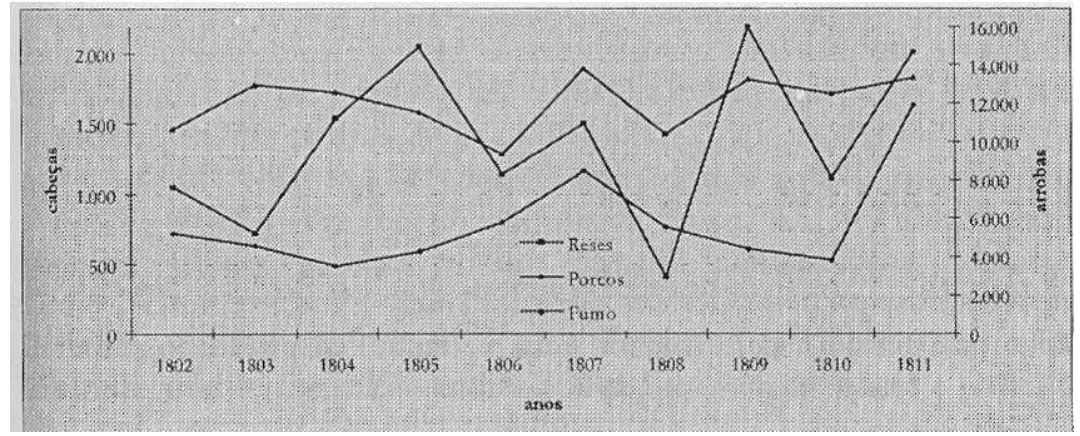

Fontes:Arquivo Nacional, Coleção Casa dos Contos de Ouro Preto, vol. 1433.

Quanto aos ritmos da produção agrária, independentemente das conjunturas, há dois movimentos estruturais: em primeiro lugar, a produção agrária foi crescente em todo o período colonial e imperial, porquanto a taxa de crescimento populacional fora crescente, e é a 
produção das lavouras que a sustentou; em segundo lugar, o movimento dos preços fora declinante, desde, pelo menos, 1716. Lembremos mais uma vez que a queda continuada dos preços interferia relativamente nos ajustes individuais porque o dizimeiro podia, e normalmente aguardava com ansiedade, os momentos de 'repiquete' (altas sazonais acentuadas), nos quais alargava seus lucros, muito mais do que naquelas épocas em que a produção agrícola era grande, e, em decorrência, os preços baixos. Era exatamente devido a esse binômio - decrescimento da produção agrária/preços em alta (estes explicados por aquele) que conseguiam garantir ganhos contínuos os contratadores.

Entre $1722-5$ e 1734-7, o crescimento do valor da arrematação trienal dos dízimos acompanhou o crescimento da produção agrícola e pecuária. A queda do valor da arrematação desse contrato entre os triênios de 1725-5 e 1728-31 deve ser atribuída em parte à queda continuada do nível dos preços. O arranque do valor do contrato a partir de 1728 expressa o movimento cronologicamente coincidente da ocupação da Demarcação Diamantina e de Minas Novas, numa conjuntura em que os preços já não interferiam muito, ou seja,já se achavam minimamente estabilizados. A partir de 1734-7, apesar do crescimento da produção agrária, o valor da arrematação não mais se sustentou no nível máximo ocorrido nesse triênio, porque o nível dos preços baixara ainda mais. Esse nível permaneceu relativamente constante durante toda a segunda metade do século XVIII. Desde 1738-41 torna-se bem visível o movimento característico posterior: redução da participação dos dízimos das Comarcas de Vila Rica (Ouro Preto e Mariana) e de Sabará, e crescimento da participação dos dízimos da Comarca do Rio das Mortes. Esse movimento, aliás, adequa-se à flutuação da participação da população por comarca da Capitania, verificado entre 1723 e 1749. Finalmente, a partir de 1744-7, as flutuações dos valores dos contratos dos dízimos passaram a corresponder à variação da produção agrária do conjunto de freguesias participantes dos circuitos inter e intra-regionais, e que de modo geral foi determinada pelas variações da produção mineral. Mesmo o último movimento de ocupação - Paracatu - não interferiu significativamente.

No triênio de 1744 a 1747, os circuitos internos de abastecimento, organizados à roda dos núcleos mineradores, já se achavam consolidados. Eram eles que definiam as "regiões" da Capitania, seus espaços econômicos regionais: Minas Novas (Itacambira, Itamarandiba e Rio Pardo, inclusive);Demarcação Diamantina (Serro e Conceição do Mato Dentro e Rio Vermelho, inclusive); Pitangui e as "minas gerais" (Ouro Preto, 
Mariana, Sabará e Caeté), onde se efetuava a mais ampla articulação entre a zona curraleira sanfranciscana, o sul de Minas e o Rio de Janeiro; e o sul de Minas (cf. abaixo os quadros 1 e 2 e o gráfico 6).

Quadro 1. Valor anual dos dízimos por comarca da Capitania de Minas Gerais em libras de ouro em pó- 1722-1750

\begin{tabular}{|c|c|c|c|c|c|c|c|c|c|}
\hline $\begin{array}{l}\text { \Períodos } \\
\text { Comarcas } \backslash \\
\end{array}$ & $1722-5$ & $1725-8$ & $1728-31$ & $1731-4$ & $1734-7$ & $1737-8$ & $1738-41$ & $1741-4$ & $1744-50$ \\
\hline Vila Rica & & 210,6 & {$[174,8]$} & {$[214]$} & 261,3 & 192,5 & 264 & 213,3 & \\
\hline Sabará & & 123 & [102] & [125] & 170,6 & {$[176]$} & 176 & 133,3 & \\
\hline Rio das Mortes & & 70 & {$[58]$} & {$[71]$} & 104,1 & {$[100]$} & 96 & 186,6 & \\
\hline Total & 240,3 & 403,6 & 335 & 409 & 536,1 & 468,7 & 536 & 533,3 & 471 \\
\hline
\end{tabular}

Fontes: Arquivo Público Mineiro, CC 1048 e 1049: Livros de arrematações de direitos e contratos (172444/1724-50); dados para 1728-31 tomados da Carta do Governador ao Rei, de 10 de julho de 1727 [Arquivo Público Mineiro, SC 23], in: Revista do Arquivo Público Mineiro, 31(1980): 228-9; as cifras entre colchetes apenas expressam valores hipotéticos médios com base nos totais dos anos anteriores e posteriores.

Gráfico 6.Valores anuais dos dízimos na Capitania de Minas Gerais (1722-1750)

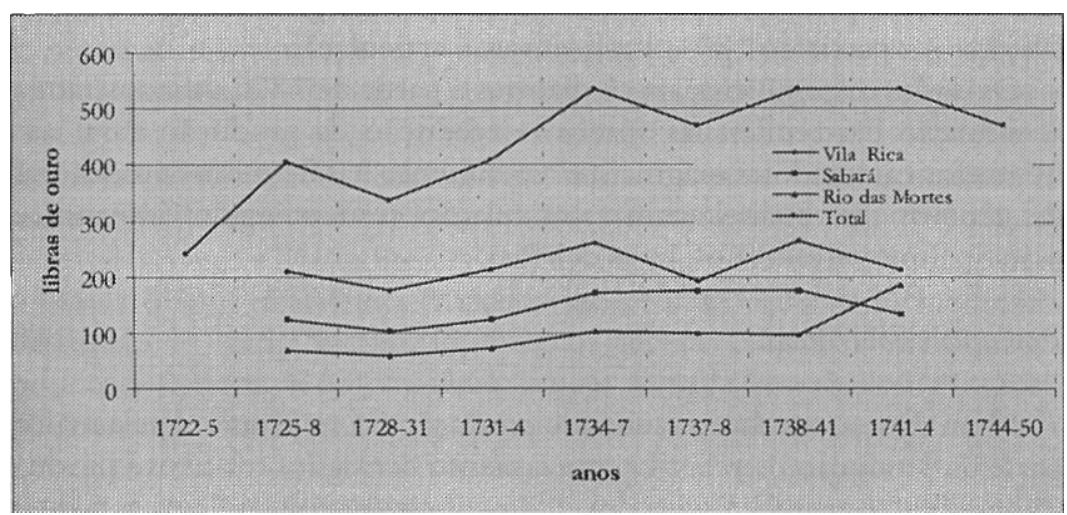

Quadro 2. População escrava (\%) por Comarca de Minas Gerais - 1723-49

\begin{tabular}{lrrr}
\hline Comarcas & 1723 & 1735 & 1749 \\
\hline Vila Rica & 54,73 & 49,46 & 44,48 \\
Rio das Mortes & 13,12 & 14,91 & 15,53 \\
Sabará & 27,44 & 25,15 & 23,60 \\
Serro & 4,69 & 10,46 & 7,90 \\
\hline
\end{tabular}

Fontes: cf. fontes do gráfico; dados sistematizados apud Carrara,A.A. Agricultura e Pecuária na Capitania de Minas Gerais; 1674-1807. Rio de Janeiro, UFRJ, 1997 (tese de doutorado).p. 58. 
Entre 1750 e 1807 , todas as freguesias das zonas mineradoras cujos dados são mais completos experimentaram acentuadíssima queda de produção agrária, derivada da queda do nível de mercantilização provocada pela escassez de ouro: as cifras correspondentes às freguesias de Rio Acima, São Bartolomeu, Rio das Pedras, Sabará, Casa Branca, Cachoeira do Campo, Sumidouro, Furquim e São Sebastião são as mais críticas. Na Demarcação Diamantina, a queda ocorre um pouco mais tardiamente, em razão do tempo diferente de suas lavras diamantíferas. A mesma sorte tiveram as freguesias dos currais, tradicionais abastecedoras de carne. Paracatu resume os movimentos dessas duas naturezas.

Por outro lado, as freguesias da Comarca do Rio das Mortes (à exceção de Prados), estabilizaram-se. As regiões da fronteira oriental, como Cuieté e Rio Piracicaba, não têm seus dízimos aumentados, mesmo com suas populações em crescimento intenso, dado que eram predominantemente camponesas. É, contudo, nas freguesias ao sul da Capitania que vamos encontrar o crescimento mais acentuado, desde a metade do século XVIII, o que revela a articulação precoce com o mercado do Rio de Janeiro. Dízimos, a entrada de mercadorias pelo Registro da Mantiqueira, principalmente, e a exportação de gêneros pelo mesmo Registro, a partir de 1801 , explicam essa articulação.

Os dados disponíveis para os dízimos a partir de 1808 demonstram a acentuação das tendências anteriores: redução da produção rural nas freguesias mineradoras originais, e crescimento nas freguesias produtoras de gêneros que estabeleciam a articulação com mercados internos e principalmente externos. João del Rei.

\section{Produção e concentração}

Além disso, o modo escravista de produção foi responsável pela maior parte da produção mercantil: o cruzamento dos dados relativos à produção agrária (por intermédio dos dízimos) com os inventários e as listas nominativas do mesmo período demonstram-no. Igualmente podem ser cruzadas as listas dos maiores passadores de mercadorias.

Quanto aos dízimos, há uma relativa correspondência entre o seu valor e o escravismo, dado que é exatamente a porção mercantil da produção que é avençada. Em 1826, a freguesia de Campanha aparecia com o maior dízimo em razão não da porcentagem elevada de escravos, mas porque concentra mais de um quarto da população total do termo. A mesma observação vale para a freguesia de Pouso Alegre, na qual viviam quase $14 \%$ do total da população do termo de Campanha. Isto 
significa que no valor do dízimo de ambas as freguesias incluía-se também a pequena produção camponesa excedente destinada ao mercado. Já as freguesias de Itajubá, Caldas e Santa Catarina, cuja participação da população escrava em relação ao total da população de cada uma das freguesias era elevada (27 a 31\%), devem exatamente a essas taxas elevadas o valor também mais alto da produção agrária. É o que explica porque a freguesia de Itajubá, mesmo tendo uma população total pequena, possuía não apenas a maior taxa de participação da população escrava no total da freguesia, como a que tinha o maior número de pagadores de dízimo do termo.Já os valores menores do dízimo das freguesias de Camanducaia, Sapucaí, Douradinho e Ouro Fino, explicam-se tanto pelas taxas mais baixas de participação da população escrava na população total de cada uma das freguesias, quanto pela menor participação da população de cada uma das freguesias na população do termo. Aos números referentes à população total de cada uma das freguesias também está relacionada a cifra respeitante ao número de lavradores contribuintes do dízimo.

Não obstante essas observações, qualquer inferência a partir das cifras dos dízimos deve ser sempre feita com cautela. As correspondências mencionadas valem apenas para as freguesias agrícolas, isto é, aquelas onde a produção mercantil era principalmente um gênero produzido nas lavouras - as quais, dado o baixo nível técnico dos modos materiais de produção existentes, demandavam muita mão-de-obra, especialmente escrava. Já Pitangui, que não era a mais extensa nem a mais populosa das freguesias (Cunha Matos lhe atribuiu cerca de 26.000 habitantes),possuía o maior dízimo de Minas, em razão do produto que ao mercado era destinado - gado vacum. O mesmo vale para Simão Pereira, com poucos lavradores (163), mas com a mais elevada taxa de concentração por contribuinte. É em Simão Pereira que se encontrava a mais acabada personificação da categoria econômica do grande proprietário fundiário escravista: o fazendeiro José Inácio Nogueira da Gama, que em 1826 pagou Rs 1:037\$600 do dízimo correspondente à sua produção de café.

Não se pode esquecer, portanto, que os valores do dízimo correspondiam aos valores da produção agrária mercantilizada. A mobilidade

\footnotetext{
Para os dados pormenorizados disponíveis para o termo de Campanha no primeiro quartel do século XIX, cf. Carrara, A. A. Contribuição para a História Agrária de Minas Gerais; séculos XVIII e XIX. Mariana: Edufop, 1999, pp. 83-5.
} 
espacial das produções mais importantes explica uma parte considerável dessas flutuações dos valores de algumas freguesias. Em 1786 e em 1805, a maior produção agrícola — especialmente milho e feijão - provinha da fazenda da Jaguara, em Santa Luzia (cerca de Rs $400 \$ 000$ anuais de dízimo). Em 1826, as cifras das freguesias de Simão Pereira e Pitangui mostram como novos gêneros, como o café e o gado, afetaram estas cifras.

Oposta a este quadro era a situação das antigas freguesias mineradoras, cujos rendimentos agrícolas estagnaram-se ao nível do que por metáfora denominei 'metabolismo social básico', definido pelos limites da subsistência: a freguesia de Itatiaia, por exemplo, que em 1750 contava com 79 lavradores responsáveis por um dízimo total de 713 mil réis, em 1805 contava com apenas quinze, e um rendimento total de $15 \$ 300$. Em 1811 e 1812, eram onze os lavradores, e entre 1816 e 1818, apenas dez. Até 1822, o número permaneceu estável em torno de treze lavradores, o mesmo acontecendo com seu dízimo, nunca superior a $17 \$ 413$ (1823).

Além disso, deve-se atentar para a participação dos lavradores por faixa de contribuição decimal, isto é, para o grau de concentração da produção rural. O fato geral - e em larga medida, óbvio, é que a produção destinada ao mercado é muito concentrada. Mas essa concentração, devido a situações históricas específicas, tem graus diversos, expressos pelas diferentes faixas de contribuição. As pesquisas ulteriores poderão determinar a natureza e as razões destas especificidades.

Note-se sempre que o número de pagadores dos dízimos considerados com suas famílias, e o número total de escravos da Capitania nas épocas correspondentes, não preenchem o número de todos os seus habitantes. Logo, os dízimos não exprimiam toda a produção agrária; deixava de fora a pequena produção para o auto-consumo. Exprimiam apenas a produção destinada ao mercado; são cifras que expressavam essencialmente a produção de caráter escravista. Essencial mas não exclusivamente já que comportava também a participação - eventual ou permanente - de alguns lavradores com produção familiar lançada ao mercado, com ou sem o recurso à mão-de-obra escrava ou de outro tipo: os números das oitavas de ouro devidos por cada lavrador devem ser lidos como os gêneros produzidos pelas unidades escravistas ou pelos poucos camponeses que, felizardamente, participaram do mercado naquele momento em que a avença fora feita: grãos, efeitos da cana, fumo, toucinho e carnes. Já a produção hortense era expressa pelas miunças.

A comparação entre as listas dos pagadores de dízimo e do censo de 
1804 da freguesia do Furquim do termo de Mariana é reveladora a esse respeito. ${ }^{6}$ Como a análise dos dízimos por freguesias exige o conhecimento do exato território de cada uma delas, advirta-se desde já, que o recenseamento de 1804 refere-se ao distrito do Furquim, portanto, apenas a uma parte de sua freguesia, cujos limites orientais eram o povoado de São Gonçalo do Ubá (atual Acaiaca). Isto significa que um grande número de lugares pertencentes à freguesia não estavam aí incluídos, assim como os proprietários em Furquim domiciliados alhures. Por conseguinte, a lista dos dízimos, que abrangia toda a freguesia, incluía os lugares excluídos do recenseamento de 1804 (Ponte Nova, Bom Retiro, Barreto, Rasa, p. ex.). Feita essa observação, é possível agora rastrear ambas as listagens. Dos 142 pagadores de dízimo dessa freguesia em 1805,63 tiveram seus nomes inscritos na listagem de 1804, o que deixa de fora 79 pagadores. Desses últimos, a maior parte era domiciliada nos lugares acima mencionados, especialmente Ponte Nova, Bom Retiro, Gesteira e capela do Barreto. Essa comparação permite também verificar uma certa correspondência entre o tamanho das "fábricas" de cada proprietário e o valor do dízimo pago. Assim é que um proprietário de 47 escravos e de um engenho de aguardente de que extraía cachaça e rapaduras, pagava 15 oitavas de dízimo. Em contraste, um ferreiro não proprietário de escravos, pagava dois vinténs de ouro de dízimo. Deve-se repetir que não há proporcionalidade, mas relativa correspondência. Não se pode esquecer que o censo não informava as idades nem o estado de saúde dos escravos, fatores fundamentais para a determinação do rendimento das unidades de produção. Mesmo com quatorze escravos, um lavrador fora tributado em Rs $2 \$ 250$, enquanto seu vizinho, proprietário de dez escravos, pagara Rs $11 \$ 250$.

\section{Escravismo e campesinato}

À guisa de conclusão, devem ser feitas aqui algumas observações com respeito à relação entre este modelo e a estrutura fundiária. Em primeiro lugar, a existência na Capitania de pelo menos duas lógicas econômicas demonstrada pela posse ou não de escravos produz diferenças nos padrões de propriedade do solo que devem ser identificadas e caracterizadas através de estudos não apenas sobre a ocupação, mas essencialmente sobre o uso do solo, porquanto a terra é o principal

Arquivo Nacional, Coleção Casa dos Contos de Ouro Preto, avulsos, cx. 247, grupo 01. 
meio de produção nessa sociedade rural. Neste sentido, é necessário que sejam empreendidos estudos que esclareçam a história da propriedade rural. Para a Zona da Mata central de Minas Gerais, alguns resultados já se encontram disponíveis.

No caso específico de Minas, deve-se ter sempre em mente uma diferença importante entre o que ocorrera nas regiões mineradoras e nos currais. Por compreender espaços econômicos regionais variados, os movimentos internos de ocupação territorial também foram variados. ${ }^{8}$ O primeiro movimento de ocupação ocorrera entre 1674 e 1690. Em 1674, os irmãos Julião e Manuel Afonso Sertão, receberam cada um três e meia léguas quadradas no rio das Velhas. Dezesseis anos depois, um grande grupo de paulistas recebia cada qual quatro léguas em quadra nos sertões do rio Pardo e Doce. O segundo movimento foi inaugurado com a descoberta das minas, a partir de 1696. Há, contudo, um ritmo geral, não obstante as cartas concedidas entre 1710 e 1714 apenas cadastrarem alguns proprietários rurais da Capitania, e flagrarem o 'primeiro movimento', i. e., o da ocupação das terras dos distritos mineradores, também conhecido como "minas gerais", do Caminho Novo (por onde transitava em número crescente pessoas e mercadorias em demanda das minas), do Caminho Velho, da região da serra das Vertentes e dos currais situados especialmente nos vales dos rios das Velhas e Paraopeba e do Serro. A esse primeiro movimento, seguiramse os processos ordinários e rotineiros do mercado de propriedades rústicas, e do lançamento de posses nas áreas de fronteira (como, por exemplo, nos vales dos rios Piranga, Piracicaba, Chopotó,Verde). Além desse movimento de rotina, há outro, determinado pelas descobertas minerais: o das ocupações de Minas Novas e da Demarcação Diamantina, a partir de 1727, e de Paracatu, desde 1744. As descobertas das minas goianas igualmente se refletiram na ocupação, a partir de 1736 , de toda a região noroeste da Capitania (vales dos rios Paracatu e Urucuia,

Cf. Carrara, Angelo Alves. Estruturas Agrárias e Capitalismo: contribuição para o estudo da ocupação do solo e da transformação do trabalho na zona da Mata mineira (séculos XVIII e XIX). Mariana: Edufop, 1999.

Identificamos os seguintes espaços regionais vigentes durante o período colonial as freguesias mineradoras dos termos das Vilas de Sabará, Caeté, Mariana e Ouro Preto; o Caminho Novo (do rio Paraíba do Sul até Carandaí); a serra das Vertentes, o CaminhoVelho e os termos das Vilas de São João e São José del Rei; os currais: os vales dos rios das Velhas e Paraopeba; o Serro e arraial do Tijuco; o 'continente' de Minas Novas; as minas e os caminhos de Goiás: os vales do Pacuí e do Mangai. 
principalmente). É necessário observar que a essa movimentação corresponderam as flutuações da produção agrícola da Capitania de Minas Gerais, expresso nos valores das arrematações dos contratos trienais dos dízimos, que o segundo estudo deste trabalho estuda.

Quanto às fronteiras, a maior parte das terras foram aí ocupadas "por lançamento de posses e por título de as fabricar". A possibilidade de ocupação de terras devolutas ou em áreas de fronteira foi ademais a solução estrutural encontrada por muitos no interior de um sistema agrário que demandava certa extensão de "matos virgens e capoeiras", ao lado das terras lavradias. No caso das pequenas unidades de produção para o consumo próprio, a necessidade de mais terras, isto é, de novas unidades de produção para atender ao crescimento demográfico, era respondida com o avanço da fronteira.' Por fim, lembremos que a Capitania de Minas conheceu também duas propriedades fundiárias segundo o padrão senhorial europeu: o Vínculo do Jaguara, instituído em 1787, e o Morgado Guedes de Brito, instituído ainda no século XVII. Mais tarde este morgadio foi incorporado ao patrimônio da Casa da Ponte.

Sobre os ritmos da ocupação do solo cf. Carrara, Ângelo A. Contribuição para a História Agrária de Minas Gerais, séculos XVIII e XIX. Mariana: Edufop, 1999. 